International Journal of Fuzzy Logic Systems (IJFLS) Vol.5, No.4, October 2015

\title{
A FuzZY LOGIC BASEd SCHEME For THE PARAMETERIZATION OF THE INTER-TropicAL DISCONTINUITY FOR USE IN NUMERICAL WeATHer Prediction Models Over Nigeria
}

\author{
Okpara Okechukwu Dominic \\ National Weather Forecasting and Climate Research Centre (NWFCRC), Nigerian \\ Meteorological Agency (NIMET), Nnamdi Azikiwe International Airport, Abuja-FCT, \\ Nigeria.
}

\begin{abstract}
In this paper, a Fuzzy Logic based scheme for the parameterization of the Inter-Tropical Discontinuity (ITD) over Nigeria was presented. The scheme was developed in order to provide a computational basis for Numerical Weather Prediction (NWP) modeling over Nigeria. The scheme uses a fuzzified $2.5^{0}$ by $5^{0}$ resolution grid box or 10 rows by 4 columns (10x4) matrix with the rows classified into 10 zones. The two extreme zones represented by the five (5) boundary points or two-dimensional (2-D) lattice nodes $\left(O_{1}-\right.$ $\mathrm{O}_{5}$ ), define the matrix boundaries or lattice edges, and hence, the meridional limits of the ITD position. The scheme is simple enough to be included as an ITD parameterization by NWP modelers over West Africa.
\end{abstract}

\section{KEYWORDS}

Numerical Weather Prediction, Fuzzy Logic System, NWP, Inter-Tropical Discontinuity, ITD.

\section{INTRODUCTION}

According to [1], some of the essential characteristics of fuzzy logic are as follows:

1. In fuzzy logic, exact reasoning is viewed as a limiting case of approximate reasoning.

2. In fuzzy logic, everything is a matter of degree.

3. Any logical system can be fuzzified.

4. In fuzzy logic, knowledge is interpreted as a collection of elastic or, equivalently, fuzzy constraint on a collection of variables

5. Inference is viewed as a process of propagation of elastic constraints.

Fuzzy Logic is defined as a type of logic that recognizes more than simple true and false values. With fuzzy logic, propositions can be represented with degrees of truthfulness and falsehood. For example, the statement, today is sunny, might be $100 \%$ true if there are no clouds, $80 \%$ true if there are a few clouds, $50 \%$ true if it's hazy and $0 \%$ true if it rains all day [2]. Fuzzy rules operate using a series of if-then statements. For instance, if $X$ then A, if $y$ then $b$, where A and B are all sets of $X$ and $Y$. A Fuzzy subset $A$ of a (crisp) set $X$ is characterized by assigning to each element $\mathrm{x}$ of $\mathrm{X}$ the degree of membership of $\mathrm{x}$ in $\mathrm{A}$ (e.g. $\mathrm{X}$ is a group of people, A the fuzzy set of old people in X) [3]. Fuzzy Logic can control nonlinear systems that would be difficult or impossible to model mathematically [4].

DOI : $10.5121 /$ ijfls.2015.5401 
On the other hand, the Inter-Tropical Discontinuity (ITD) is the demarcation line between north/north-eastern trade winds from the Sahara (hot, dry and dusty) region and south/southwestern winds from Atlantic Ocean (cool and moist) [5], as seen in Figure 1. The ITD position is determined by drawing a line through the 15 degrees Celsius dew point temperature on surface plots of 1200 GMT data each day. For data-sparse areas, the 10metres-wind direction convergence line at 0000 GMT is used. The latitude of the ITD is determined at each 5 degrees of longitude [6]. A fuzzy logic model in classifying atmospheric circulation patterns has been implemented [7].

The weather conditions over West Africa are difficult to predict because they are based on the nature of numerous entities called the "forcing functions" which affect the West African mesoscale and synoptic - ocean, land, atmospheric - weather systems. The ITD position is being affected by a number of synoptic- and meso-scale forcings. These forcings include: waves on the subtropical jet, mid-level African easterly waves (AEWs) and deformation by convective cold pools [8]. Differences in the atmospheric models and data assimilation methods used to generate analysis data can lead to substantial differences, particularly in areas with a sparse observational network [8].

Fuzzy methods in weather prediction system have been carried out in order to improve the technique of persistence climatology [9]. A model of a fuzzy logic based system for rainfall prediction based on four factors: Azores high pressure cell, St. Helena high pressure cell, Intertropical discontinuity and Wind as the predictors has been developed [10].

\section{Positlons moyennos du FIT: decade 3 (Nolre), docado 2 (Bloue) et décade 1 (Rouge) de Mal 2012 ITD mean position dekad 3 (black), dekad 2 (blue) and dekade 1 (Red) of May 2012}

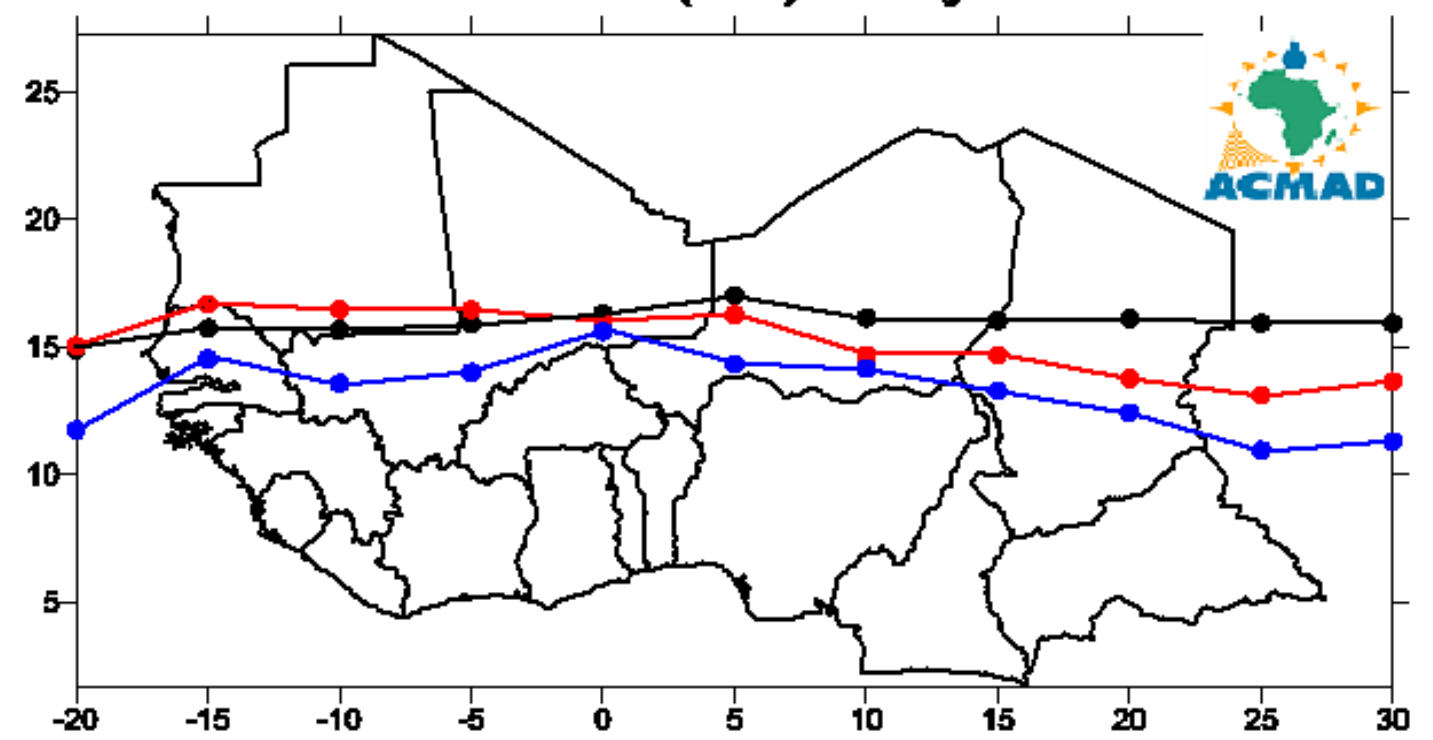

Figure 1: Dekadals ITD Position (Source: African Centre of Meteorological Application for Development (ACMAD); Centre [Centre Africain pour les Applications de la Météorologie au Développement]) 


\section{MAterials ANd Methods}

The Conceptual Development of this scheme is based on the following requirements:

A. The Scale: Let the scale constant parameters for Longitude (Long.) and Latitude (Lat.) be $\mathrm{x}$ and $\mathrm{y}$ respectively. Let the scale variable parameter for the ITD be $\mathrm{O}$. The coordinate location of Nigeria can then be expressed as:

Long.: $3^{0} \mathrm{E}<\mathrm{x}<15^{0} \mathrm{E}$, Lat.: $4^{0} \mathrm{~N}<\mathrm{y}<14^{0} \mathrm{~N}$

So we can choose a suitable scale that encapsulates Nigeria, such as:

Long.: $0^{0} \mathrm{E}<\mathrm{x}<20^{0} \mathrm{E}$, Lat.: $0^{0} \mathrm{~N}<\mathrm{y}<25^{\circ} \mathrm{N}$

Note: the choice of $25^{0} \mathrm{~N}$ over $20^{0} \mathrm{~N}$, because sometimes the ITD has been found to exceed $20^{0} \mathrm{~N}$ Latitude over West Africa.

B. The Grid box: From the chosen scale we can make a suitable grid box of $2.5^{0}$ by $5^{0}$ to accommodate the scales on a two-dimensional (2-D) plane as shown in Figure 2.

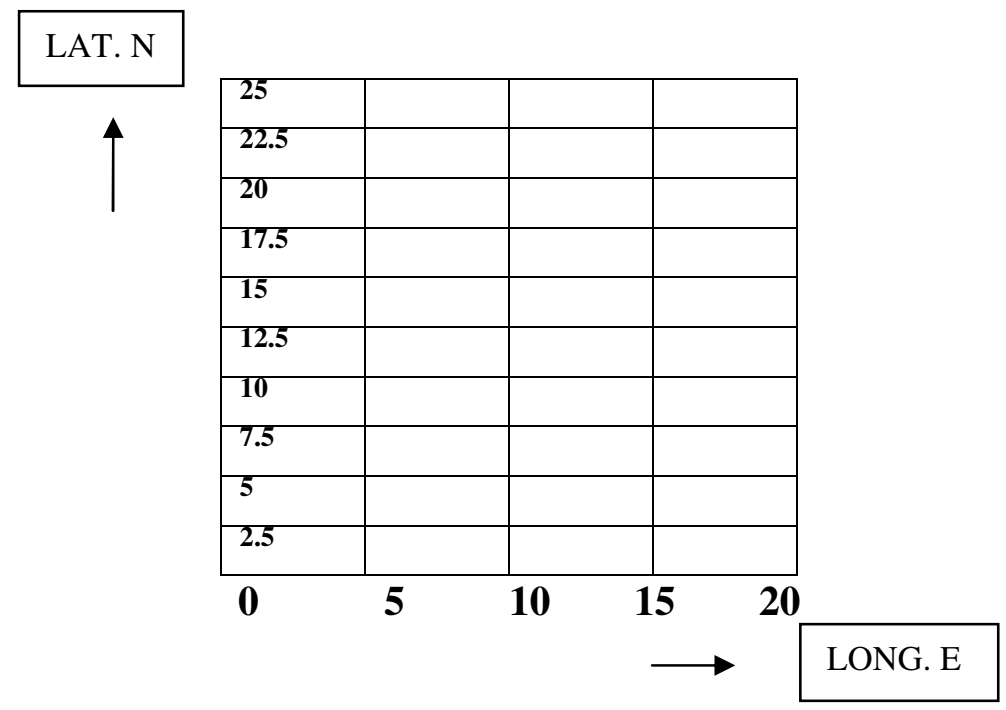

Figure 2: A $2.5^{0}$ by $5^{0}$ two-dimensional scale for the scheme

The $2.5^{0}$ by $5^{0}$ grid box resulted in a 10 by $4(10 \times 4)$ matrix with forty (40) cells due to the uneven distribution of the chosen scale as shown in Figure 3. The matrix four (4) corner cells were systematically labeled $(1,1),(1,4),(10,1)$ and $(10,4)$.

\begin{tabular}{|l|l|l|l|}
\hline 10,1 & 10,2 & 10,3 & 10,4 \\
\hline 9,1 & 9,2 & 9,3 & 9,4 \\
\hline 8,1 & 8,2 & 8,3 & 8,4 \\
\hline 7,1 & 7,2 & 7,3 & 7,4 \\
\hline 6,1 & 6,2 & 6,3 & 6,4 \\
\hline
\end{tabular}


International Journal of Fuzzy Logic Systems (IJFLS) Vol.5, No.4, October 2015

\begin{tabular}{|l|l|l|l|}
\hline 5,1 & 5,2 & 5,3 & 5,4 \\
\hline 4,1 & 4,2 & 4,3 & 4,4 \\
\hline 3,1 & 3,2 & 3,3 & 3,4 \\
\hline 2,1 & 2,2 & 2,3 & 2,4 \\
\hline 1,1 & 1,2 & 1,3 & 1,4 \\
\hline
\end{tabular}

Figure 3: A 10 by 4 matrix for the scheme

The $10 \times 4$ matrix of Figure 3 can be represented as a 2-D lattice as shown in Figure 4, with lattice points $\left(a_{1}-a_{5}\right)$ to $\left(i_{1}-i_{5}\right)$ and boundary lattice points or nodes $\left(o_{1}-o_{5}\right)$.

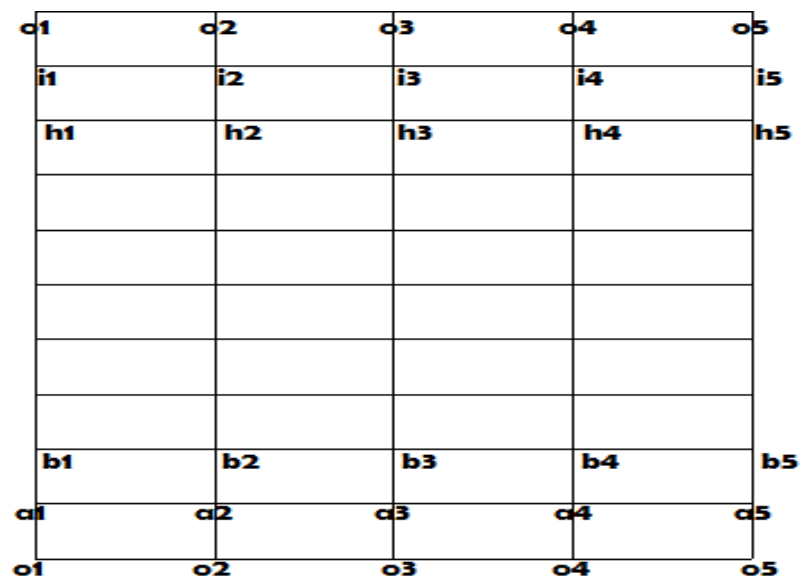

Figure 4: Lattice points (or nodes) nomenclature for the scheme

Note that the boundary nodes $\left(\mathrm{o}_{1}-\mathrm{O}_{5}\right)$ appear north and south of the 2-D lattice in line with the North-South meridional oscillation of the ITD position. The matrix of Figure 3 or the lattice of Figure 4 can be classified into ten (10) zones, Z, as shown in Figure 5.

\begin{tabular}{|l|l|l|l|c|}
\hline 10,1 & 10,2 & 10,3 & 10,4 & ZONE 10 or ZONE \\
\hline 9,1 & 9,2 & 9,3 & 9,4 & $\vdots$ \\
\hline 8,1 & 8,2 & 8,3 & 8,4 & $\vdots$ \\
\hline 7,1 & 7,2 & 7,3 & 7,4 & \\
\hline 6,1 & 6,2 & 6,3 & 6,4 & \\
\hline 5,1 & 5,2 & 5,3 & 5,4 & \\
\hline 4,1 & 4,2 & 4,3 & 4,4 & \\
\hline 3,1 & 3,2 & 3,3 & 3,4 & \\
\hline 2,1 & 2,2 & 2,3 & 2,4 & \\
\hline 1,1 & 1,2 & 1,3 & 1,4 & ZONE 1 or ZONE A \\
\hline
\end{tabular}

Figure 5: Conceptual diagram of the ten zones, Z, used for the scheme 


\section{Generation Of The Sets For The Itd Variable Positions}

The scheme is generated from the inter-lattice boundaries from which the ITD variable, O, crosses the $2.5^{0}$ latitude axis shown within the [ ] symbol or intercepts the $5^{0}$ longitude axis shown in within the ( ) symbol. From the ITD position provided in Figure 6, one can generate the set of the ITD variable positions for use in a Numerical Weather Prediction model schematically as:

$$
O\left\{\left(o_{1}-a_{1}\right),\left(o_{2}-a_{2}\right),\left[a_{2}-a_{3}\right],\left(a_{3}-b_{3}\right),\left(a_{4}-b_{4}\right),\left[a_{4}-a_{5}\right],\left(o_{5}-a_{5}\right)\right\} .
$$

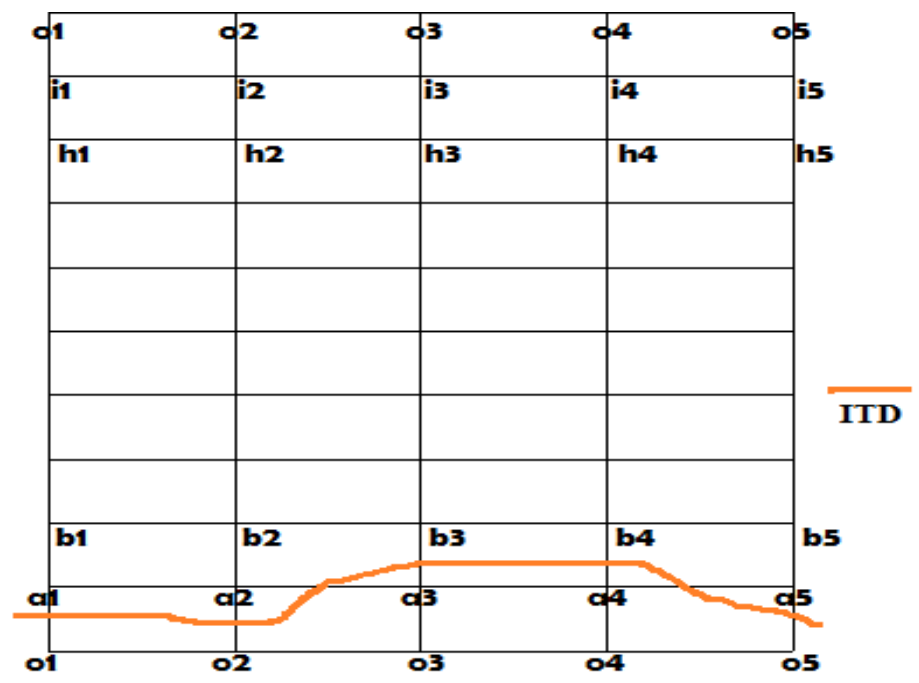

Figure 6: An example schematic diagram for the ITD

Another example is given in Figure 7 in which the generated scheme for the set of the ITD variable positions will be:

$\mathrm{O}\left\{\left(\mathrm{o}_{1}-\mathrm{a}_{1}\right),\left(\mathrm{o}_{2}-\mathrm{a}_{2}\right),\left(\mathrm{o}_{3}-\mathrm{a}_{3}\right),\left[\mathrm{a}_{3}-\mathrm{a}_{4}\right], 2\left[\mathrm{~b}_{3}-\mathrm{b}_{4}\right],\left[\mathrm{a}_{3}-\mathrm{a}_{4}\right],\left(\mathrm{o}_{4}-\mathrm{a}_{4}\right),\left[\mathrm{a}_{4}-\mathrm{a}_{5}\right],\left(\mathrm{a}_{5}-\mathrm{b}_{5}\right)\right\}$.

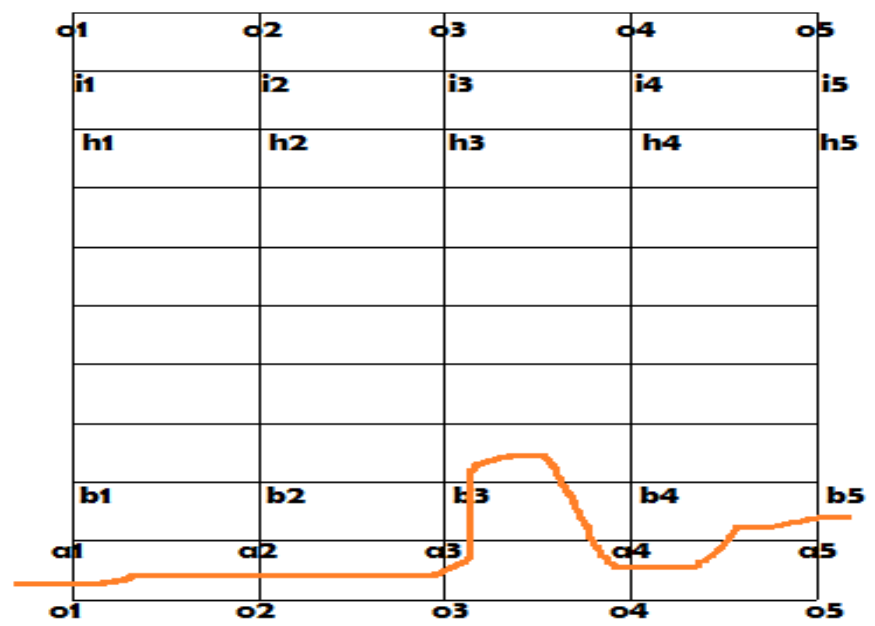

Figure 7: Another example schematic diagram for the ITD 
The location of the actual ITD line in the two example schematic models, shown in Figures 6 and 7, can be included within the sets for the ITD variable positions using an "offset" parameter, denoted by "OFF", and rounded off to one decimal place. The offset is regarded as the estimated latitudinal or longitudinal positions of the ITD variable line as it cuts across the [ ] or ( ) set boundaries. The offset and its ITD degree location are included in the scheme parameterization just after the [ ] or ( ) set boundaries. For instance, using the two examples:

A. $O\left\{\left(o_{1}-a_{1}\right),\left(o_{2}-a_{2}\right),\left[a_{2}-a_{3}\right],\left(a_{3}-b_{3}\right),\left(a_{4}-b_{4}\right),\left[a_{4}-a_{5}\right],\left(o_{5}-a_{5}\right)\right\}$

B. $O\left\{\left(o_{1}-a_{1}\right),\left(o_{2}-a_{2}\right),\left(o_{3}-a_{3}\right),\left[a_{3}-a_{4}\right], 2\left[b_{3}-b_{4}\right],\left[a_{3}-a_{4}\right],\left(o_{4}-a_{4}\right),\left[a_{4}-a_{5}\right],\left(a_{5}-b_{5}\right)\right\}$

We include their offset terms thus:

C. $\mathrm{O}\left\{\left(\mathrm{o}_{1}-\mathrm{a}_{1}\right) \mathrm{OFF}+1.3,\left(\mathrm{o}_{2}-\mathrm{a}_{2}\right) \mathrm{OFF}+1.1,\left[\mathrm{a}_{2}-\mathrm{a}_{3}\right] \mathrm{OFF}+7.5,\left(\mathrm{a}_{3}-\mathrm{b}_{3}\right) \mathrm{OFF}+2.7,\left(\mathrm{a}_{4}-\mathrm{b}_{4}\right)\right.$ $\left.\mathrm{OFF}+2.7,\left[\mathrm{a}_{4}-\mathrm{a}_{5}\right] \mathrm{OFF}+16.5,\left(\mathrm{o}_{5}-\mathrm{a}_{5}\right) \mathrm{OFF}+1.3\right\}$

D. $\mathrm{O}\left\{\left(\mathrm{o}_{1}-\mathrm{a}_{1}\right) \mathrm{OFF}+1.0,\left(\mathrm{o}_{2}-\mathrm{a}_{2}\right) \mathrm{OFF}+1.1,\left(\mathrm{o}_{3}-\mathrm{a}_{3}\right) \mathrm{OFF}+1.2,\left[\mathrm{a}_{3}-\mathrm{a}_{4}\right] \mathrm{OFF}+10.1,\left[\mathrm{~b}_{3}-\mathrm{b}_{4}\right]\right.$ $\mathrm{OFF}+10.1,\left[\mathrm{~b}_{3}-\mathrm{b}_{4}\right] \mathrm{OFF}+13.4,\left[\mathrm{a}_{3}-\mathrm{a}_{4}\right] \mathrm{OFF}+14.2,\left(\mathrm{o}_{4}-\mathrm{a}_{4}\right) \mathrm{OFF}+2.0,\left[\mathrm{a}_{4}-\mathrm{a}_{5}\right]$ $\left.\mathrm{OFF}+17.5,\left(\mathrm{a}_{5}-\mathrm{b}_{5}\right) \mathrm{OFF}+3.5\right\}$

Moreover, in a simple model analysis for operational weather forecasting over West Africa, the 1009 and 1015 isobars were used in identifying the Low Pressure and High Pressure cells respectively on the Mean Sea Level Pressure (MSLP) charts at 00 hours (UTC/GMT) for Thursday 27, August 2015; the 1015 constant pressure isolines - shown in thick blue lines surrounding the hashed blue regions - were used in locating the center values of Azores High (1019Hpa) and St. Helena High (1023Hpa) in the operational model shown in Figure 8 . The ITD position has been observed to move within the region surrounding the main 1009 isobar on the MSLP chart over Africa, this phenomenon can be explained from our knowledge of "heat lows"shown in Figure 8 with a hashed red line. For example, the real-time ITD position for the charts in Figure 8 was found to be approximately $19.0^{\circ} \mathrm{N}$. Hence, we can further introduce an average thermal or heat low parameter, $\mathrm{H}$, associated with the ITD position. 
International Journal of Fuzzy Logic Systems (IJFLS) Vol.5, No.4, October 2015
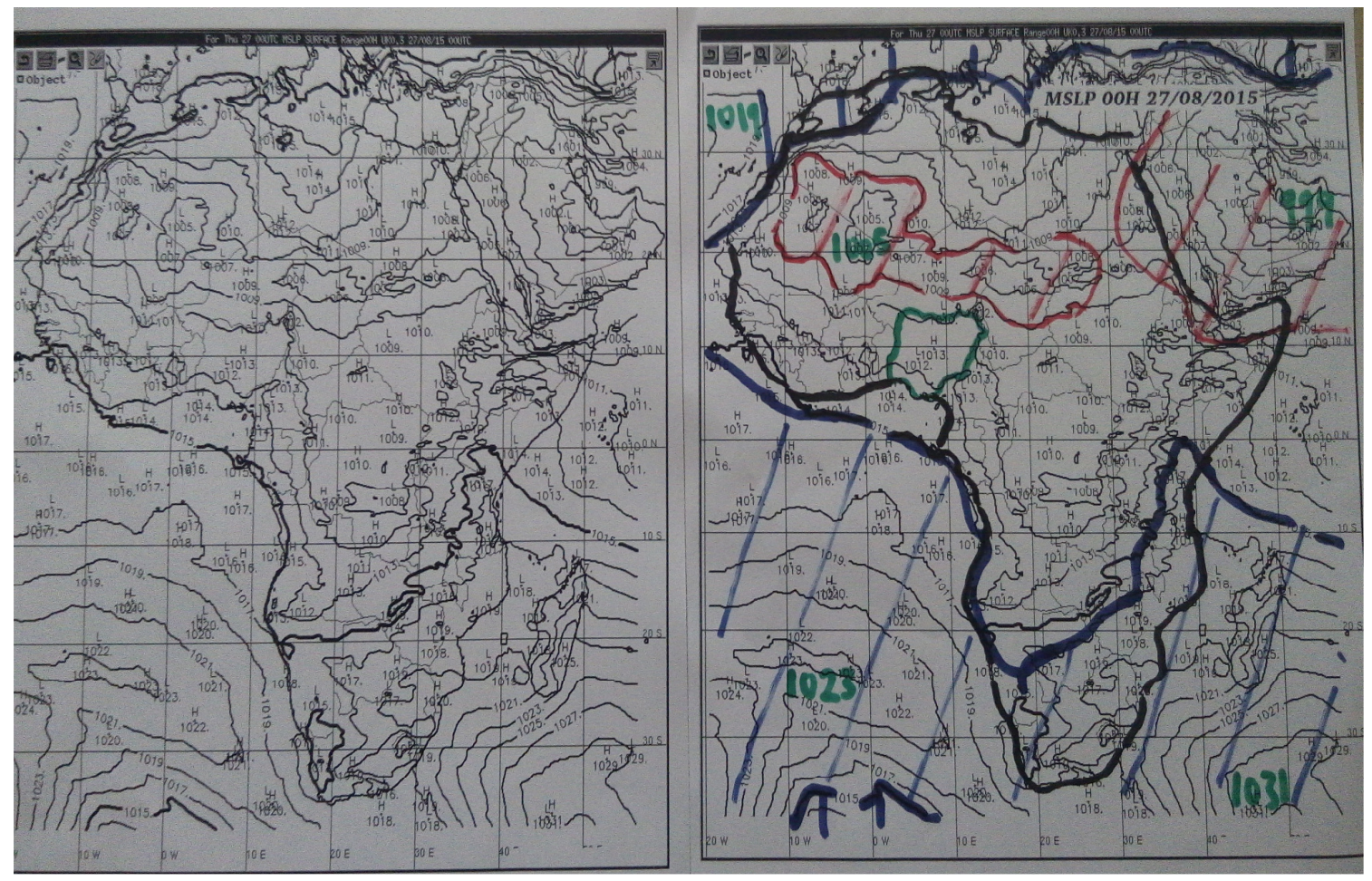

Figure 8: Left image is the unanalyzed MSLP chart. Right image is an analyzed version

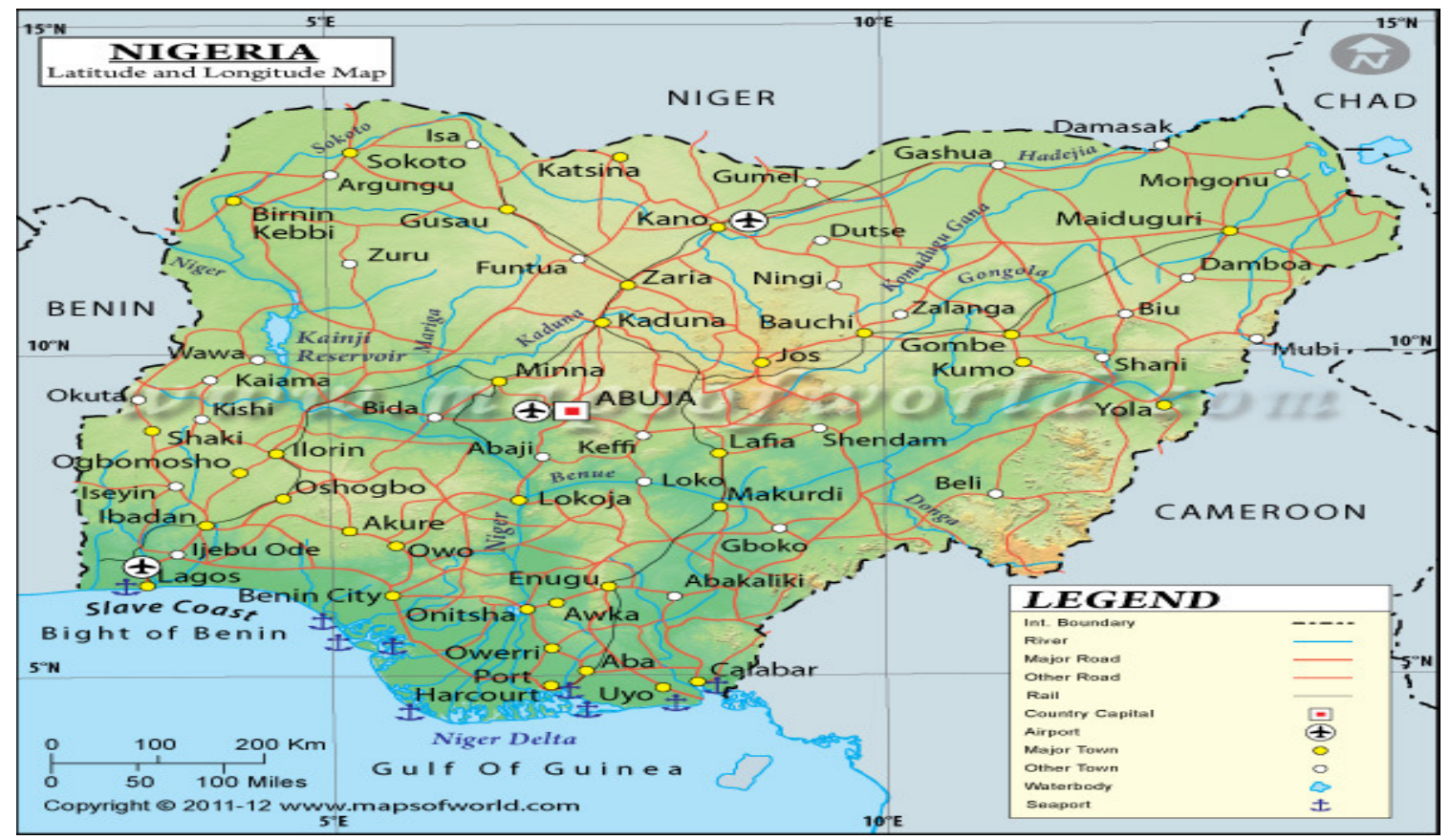

Figure 9: Location of Nigeria 
Noting the location of Nigeria from Figure 9, we can conveniently choose another scale of $5^{0} \mathrm{x}$ $15^{\circ}$ on both axes in which case the boundary midpoints are: longitudes $2.5^{\circ} \mathrm{E}$ and $17.5^{\circ} \mathrm{E}$, \{ that is, $(0+5) / 2$ and $(15+20) / 2\}$, and latitudes $3.625^{\circ} \mathrm{N}$ and $16.25^{\circ} \mathrm{N}, \quad$ that is, $(2.5+5.0) / 2$ and $(15.0+17.5) / 2\}$.

From Figures 2 and 3, the grid boxes of interest are shown in Figure 10a, and Figure 10b shows an arbitrary naming convention for $\mathrm{H}_{1}$ using $\mathrm{H}_{1} 1$ to $\mathrm{H} 8$ with each of the grid cells of interest and their corresponding zones (Z3 to Z6) for easy identification. Refer to Figure 5 for zones.

\begin{tabular}{|l|l|l|l|}
\hline 25 & & & \\
\hline 22.5 & & & \\
\hline 20 & & & \\
\hline 17.5 & & & \\
\hline 15 & 6,2 & 6,3 & \\
\hline 12.5 & 5,2 & 5,3 & \\
\hline 10 & 4,2 & 4,3 & \\
\hline 7.5 & 3,2 & 3,3 & \\
\hline 5 & & & \\
\hline 2.5 & & & \\
\hline
\end{tabular}

(a)The grid boxes of interest

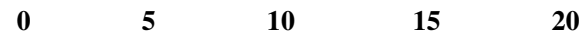

\begin{tabular}{|l|l|l|l|}
\hline $\mathbf{1 5}$ & H7 Z6 & H8 Z6 & \\
\hline $\mathbf{1 2 . 5}$ & H5 Z5 & H6 Z5 & \\
\hline $\mathbf{1 0}$ & H3 Z4 & H4 Z4 & \\
\hline $\mathbf{7 . 5}$ & H1 Z3 & H2 Z3 & \\
\hline $\mathbf{5}$ & & & \\
\hline
\end{tabular}

(b) Arbitrary naming convention for $\mathrm{H}$

Figure 10: The $5^{0}$ by $15^{0}$ two-dimensional scale

A diagrammatic sketch of the grid cells $\mathrm{H} 1 \mathrm{ZZ}$ and H6Z5 with their surrounding grid boxes (shaded) encapsulating their boundary midpoints are shown in Figure 11a and 11b respectively.

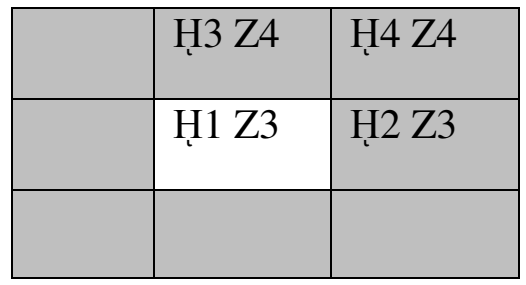

(a) $\mathrm{H} 1 \mathrm{Z3}$

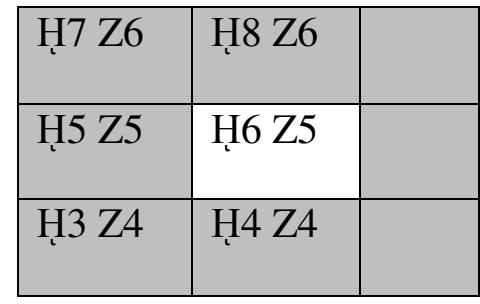

(b) $\quad$ H6 Z5

Figure 11: Diagrammatic sketch of grid boxes/cells Hุ1Z3 and Hุ6Z5

Observe that H1Z3 has 5 empty grid cells around it while H6Z5 has 3 empty cells around it. The values of these empty cells are not accounted for directly, and would be represented as unknowns, $\mathrm{U}$, in the scheme parameterization. Hence H1Z3 has 5 unknowns written as U5, and H6Z5 has 3 unknowns written as U3.

The fuzzy sets of the eight $\mathrm{H}$ parameters are as follows:

1. $\mathrm{H} 1 \mathrm{Z3}=\{\mathrm{H} 2 \mathrm{Z} 3, \mathrm{H} 4 \mathrm{Z} 4, \mathrm{H} 3 \mathrm{ZZ} 4, \mathrm{U} 5\}$; abbreviated as H1Z3U5.

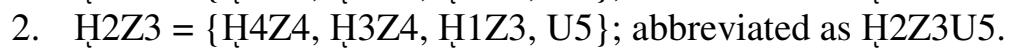


3. $\mathrm{H} 3 \mathrm{Z} 4=\{\mathrm{H} 1 \mathrm{Z3}, \mathrm{H} 2 \mathrm{Z} 3, \mathrm{H} 4 \mathrm{ZZ}, \mathrm{H} 6 \mathrm{Z} 5, \mathrm{H} 5 \mathrm{Z} 5, \mathrm{U} 3\}$; abbreviated as H3Z4U3.

4. $\mathrm{H} 4 \mathrm{ZZ}=\{\mathrm{H} 6 \mathrm{Z} 5, \mathrm{H} 5 \mathrm{Z} 5, \mathrm{H} 3 \mathrm{Z} 4, \mathrm{H} 1 \mathrm{Z3}, \mathrm{H} 2 \mathrm{Z3}, \mathrm{U} 3\}$; abbreviated as H4Z4U3.

5. $\mathrm{H} 5 \mathrm{Z} 5=\{\mathrm{H} 3 \mathrm{Z} 4, \mathrm{H} 4 \mathrm{Z} 4, \mathrm{H} 6 \mathrm{Z} 5, \mathrm{H} 8 \mathrm{Z} 6, \mathrm{H} 7 \mathrm{Z6}, \mathrm{U} 3\}$; abbreviated as H5Z5U3.

6. $\mathrm{H} 6 Z 5=\{\mathrm{H} 8 \mathrm{Z} 6, \mathrm{H} 7 \mathrm{Z} 6, \mathrm{H} 5 \mathrm{ZZ}$, H3Z4, H4Z4, U3 $\}$; abbreviated as H6Z5U3.

7. $\mathrm{H} 7 \mathrm{Z6}=\{\mathrm{H} 5 \mathrm{Z} 5, \mathrm{H} 6 \mathrm{Z}$, H8Z6, U5 $\}$; abbreviated as H7Z6U5.

8. $\mathrm{H} 8 \mathrm{Z6}=\{\mathrm{H} 7 \mathrm{Z6}, \mathrm{H} 5 \mathrm{Z} 5, \mathrm{H} 6 \mathrm{Z} 5, \mathrm{U} 5\}$; abbreviated as Hั8Z6U5.

The membership functions of the thermal parameters and their associated unknowns are shown in Figure 12.

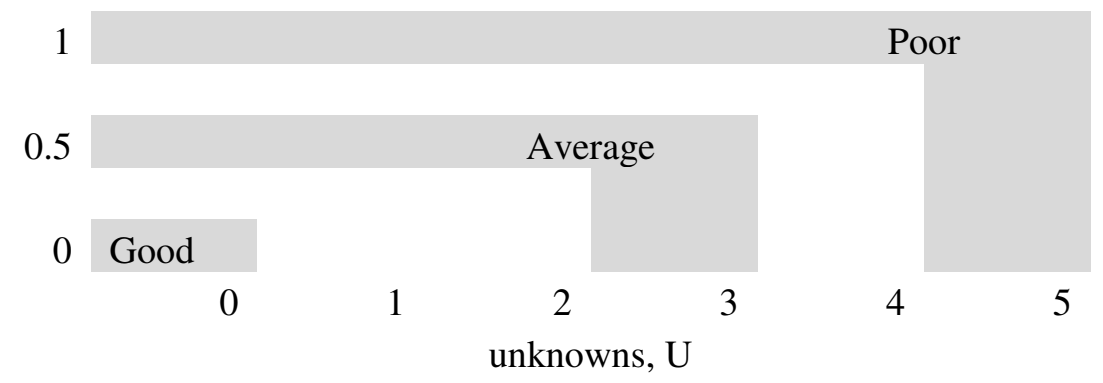

Figure 12: Membership functions of the thermal parameters

Furthermore, from Figure 12 it can be seen that $\mathrm{H}$ parameters with $\mathrm{U}$ equal to or greater than 5 has up to $100 \%$ chances of its data being derived from regions outside Nigeria (or countries sharing the same boundaries with Nigeria) in the parameterizations for $\mathrm{H}$ in the scheme; $\mathrm{H}$ parameters with the value of $U$ between 2 and 4, suggests about $50 \%$ average chances of its data being gotten from adjacent regions surrounding Nigeria; while $H$ parameters with $U$ less than 1 suggests that the $\mathrm{H}$ parameters is adequately accounted for within Nigeria by the scheme.

Incorporating the thermal/heat low parameter in the examples of Figure 6 and Figure 7, we respectively obtain the following new scheme parameterizations:

E. O $\left\{\left(\mathrm{o}_{1}-\mathrm{a}_{1}\right) \mathrm{OFF}+1.3,\left(\mathrm{o}_{2}-\mathrm{a}_{2}\right) \mathrm{OFF}+1.1,\left[\mathrm{a}_{2}-\mathrm{a}_{3}\right] \mathrm{OFF}+7.5,\left(\mathrm{a}_{3}-\mathrm{b}_{3}\right) \mathrm{OFF}+2.7,\left(\mathrm{a}_{4}-\mathrm{b}_{4}\right)\right.$ $\left.\mathrm{OFF}+2.7,\left[\mathrm{a}_{4}-\mathrm{a}_{5}\right] \mathrm{OFF}+16.5,\left(\mathrm{o}_{5}-\mathrm{a}_{5}\right) \mathrm{OFF}+1.3\right\}$

F. $\mathrm{O}\left\{\left(\mathrm{o}_{1}-\mathrm{a}_{1}\right) \mathrm{OFF}+1.0,\left(\mathrm{o}_{2}-\mathrm{a}_{2}\right) \mathrm{OFF}+1.1,\left(\mathrm{o}_{3}-\mathrm{a}_{3}\right) \mathrm{OFF}+1.2,\left[\mathrm{a}_{3}-\mathrm{a}_{4}\right] \mathrm{OFF}+10.1,\left[\mathrm{~b}_{3}-\mathrm{b}_{4}\right]\right.$ OFF+10.1, $\left[b_{3}-b_{4}\right]$ OFF+13.4, $\left[a_{3}-a_{4}\right]$ OFF+14.2, $\left(o_{4}-a_{4}\right)$ OFF+2.0, $\left[a_{4}-a_{5}\right]$ $\left.\mathrm{OFF}+17.5,\left(\mathrm{a}_{5}-\mathrm{b}_{5}\right) \mathrm{OFF}+3.5\right\} \mathrm{H}_{2} \mathrm{Z} 3 \mathrm{U} 5$

Note that in $\mathrm{E}$ above, there are no applicable or possible $\mathrm{H}$ parameters (that is, all $\mathrm{H}$ parameters = 0 ), since the ITD line did not pass the grid cells of interest. E and F are the fuzzified ITD variable positions parameterization for the ITD lines shown in Figures 6 and 7 respectively.

\section{CONCLUSiOn And RECOMMENDATIONS}

The scheme allows for the visual representation of the ITD positions on the scheme's matrix or lattice before the set of the ITD variable positions is generated. The ITD positions can oscillate North-wards and South-wards in reality so the scheme presented in this work helps in providing computational basis for representing the meridional oscillations of the ITD in a compact form especially over Nigeria. In this new form, Numerical Weather Prediction modelers can integrate 
the scheme within their model's parameterization. Note also that in reality, the incursion of the heat low into any region within Nigeria usually raises the average temperatures in those regions. Hence, the inclusion or presence of the thermal parameter, $H$, may generally suggest a rise in the average temperature over the area of interest. Therefore, $\mathrm{H}$ is significant since it provides a computational basis or template for averaging the temperature values of the surrounding grid cell variables, then associates this computed value with the ITD line passing the particular $\mathrm{H}$ grid box. However, a better way of accounting for the missing values of the unknowns, U, associated with a particular $\mathrm{H}$ should be properly formulated for this scheme, for instance, the necessary data for the $\mathrm{H}$ parameters with $\mathrm{U}$ greater than 1 may be resolved by implementing and using the boundary values from the grid cells of an adjacent or regional scheme.

The offset parameter, OFF, is significant since it provides values from 0.0 to 25.0 for the latitude axis and 0.0 to 20.0 for the longitude axis, thereby permitting us to pinpoint the exact ITD positions across both axes.

\section{REFERENCES}

[1] Zadeh, L. A. (2004). Fuzzy Logic Systems: Origin, Concepts, \& Trends. Computer Science Division, Dept. of EECS, UC Berkeley.

[2] Vangie Beal (2015). $\quad$ Fuzzy $\quad$ Logic. $\quad$ Retrieved from http://www.webopedia.com/TERM/F/fuzzy_logic.html. Accessed on 25/07/2015.

[3] Petr Hajek (2010). Fuzzy Logic. Retrieved from http://plato.stanford.edu/entries/logic-fuzzy. Accessed on May 4, 2012.

[4] Kaehler, Steven D. (1998). Fuzzy Logic. Retrieved from http://www.seattlerobotics.org/encoder/mar98/fuz/fl_part2.html. Accessed on April 28, 2012.

[5] African Centre of Meteorological Application for Development (2012). Climatic and Environmental Conditions over Africa. Climate and Health Bulletin Number 05, May 2012.

[6] Vf-Tropi (2015). "Calculated Rain line Across West Africa Defined". Retrieved from http://vftropi.com/vf-what.html accessed on July 27, 2015.

[7] Bardossy A., Duckstein L. and Bogardi I. (1995). "Fuzzy rule-based classification of atmospheric circulation patterns". International Journal of Climatology, 15: pp. 1087-1097.

[8] Alex Roberts and Peter Knippertz (2013). How well is the intertropical discontinuity (ITD) represented in different reanalysis products? Geophysical Research Abstracts Vol. 15, EGU2013-3006, 2013.

[9] Hansen B.K. (2003). "Fuzzy case based prediction of cloud ceiling and visibility": Retrieved from http://collaboration.cmc.ec.gc.ca/science/arma/bjarne/papers/presentation_2003.pdf.

[10] Ugwu C., Ejiofor C. I., Nwosu E.H. (2015). A Rainfall Predictor Based on Fuzzy Inference Model. Computing, Information Systems, Development Informatics \& Allied Research Journal. Vol. 6 No. 2. June, 2015.

\section{AUTHOR}

Okechukwu D. OKPARA is a physicist and meteorologist at the National Weather Forecasting and Climate Research Centre (NWFCRC), Nigerian Meteorological Agency (NIMET), Nnamdi Azikiwe International Airport, Abuja-FCT, Nigeria.

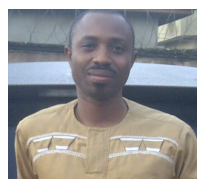

